\title{
Análise Bioenergética: Uma Revisão Sistemática da Literatura
}

\author{
Gislene Farias de Oliveira $^{(1)}$, Regina Coeli Araújo da Silva ${ }^{(2)}$, Solange Gonçalves Rolim ${ }^{(3)}$
}

Resumo: A análise bioenergética é uma proposta de compreensão da personalidade à partir do corpo, dos seus movimentos e de seus processos energéticos. Respiração, expressão à partir dos movimentos, descarga energética e acumulação de energia são funções naturais do corpo, ao tempo que são expressões dos nossos sentimentos. A análise bioenergética parte do princípio de que o corpo e a mente funcionam de maneira semelhante e se auto-influenciam mutuamente. O presente estudo é uma revisão sistemática da literatura, com a finalidade de identificar e discutir pesquisas científicas relacionadas a análise bioenergética, produzidas na última década e disponíveis em periódicos científicos. A busca bibliográfica foi realizada a partir da consulta em artigos indexados às bases de dados Medline, Scielo e Lilacs, contendo as palavras-chave (e suas associações): "Bioenergética, psicologia corporal". Os resultados nos levaram a crer que ainda é incipiente os artigos disponíveis em periódicos indexados no Brasil. Espera-se que este estudo possa despertar um maior interesse em divulgar estudos sobre essa temática, de maneira que, mais e mais pessoas possam se beneficiar dos conhecimentos desta importante teoria. Também que novos estudos sejam realizados, com um maior controle e rigor metodológicos, de forma a reafirmar os resultados benéficos da utilização dos princípios da Psicologia Corporal e da Análise Bioenergética.

Palavras-chave: Bioenergética, Psicologia corporal, Corpo, Movimento.

\section{Bioenergetics: A Systematic Review of the Literature}

\begin{abstract}
Bioenergetic analysis is the proposal for a comprehension of the personality from the body like movements and its energetic processes. Breathing, expression based on the movement, energy discharge and accumulation of energy are natural functions of the body, as which are expressions of our feelings. Bioenergetic analysis assumes that the body and mind work in a similar way and self-influence each other. The present study is a systematic review of the literature in order to identify and discuss scientific research related to bioenergetic analysis, produced in the last decade and are available in scientific journals. A literature research was performed from the consultation papers indexed to Medline, Lilacs and SciELO, containing the keywords (and their associations): "Bioenergetics, body psychology". The results led us to believe that is still incipient available articles in journals indexed in Brazil. Is expected to that this study may arouse more interest in publishing studies on this area, so that more and more people can benefit from the knowledge of this important theory. Also that new studies be conducted with a better control and methodological accuracy in order to reaffirm the beneficial results of the use of the principles of Body Psychology and Bioenergetics.
\end{abstract}

Keywords: Bioenergetics, Body Psychology, Body Movement.

\footnotetext{
${ }^{1}$ Gislene Farias de Oliveira é Professora da Universidade Federal do Ceará. Doutora em Psicologia Social e Especialista em Psicologia Clínica com ênfase na Abordagem Bioenergética. E-mail: gislenefarias@ gmail.com;

${ }^{2}$ Regina Coeli Araújo da Silva é Mestre em Psicologia Clínica pela Universidade Católica de Pernambuco, Especialista em Psicologia Organizacional, docente e coordenadora pedagógica nos cursos de especialização Lato sensu do Libertas Centro de PósGraduação e Pesquisa, Recife-PE. E-mail: regina@ libertas.com.br;

${ }^{3}$ Solange Gonçalves Rolim é Psicóloga pela Universidade Federal da Paraíba, atuando nas áreas Clínica e Organizacional. E-mail: solange-grolim@ig.com.br.
} 


\section{Introdução}

A Análise Bioenergética é um termo criado à partir dos estudos desenvolvidos pelo psicanalista Wilhelm Reich. Discípulo de Sigmund Freud, desenvolveu os princípios do que denominou de terapia corporal nos idos de 1930. Seu trabalho levou em conta a expressão corporal natural, como expressão dos sentimentos e a busca do entendimento dos significados da personalidade, associados a expressões corporais naturais. Dava ênfase a respiração e a livre expressão através dos movimentos expontâneos do corpo, como forma de alívio das tensões emocionais. Posteriormente, John Pierrakos e Alexander Lowen, seus discípulos diretos, ampliaram os estudos de Reich, dando forma a um método que ficou conhecido como Análise Bioenergética. Hoje, após explorarem diferentes possibilidades, a análise bioenergética envolve trabalhos com o corpo que vão desde a liberação das tensões, passando por posturas que facilitam as vibrações naturais do corpo, além de outros movimentos que tornam esse trabalho uma importante ferramenta, no processo terapêutico (MONTEIRO, 2007).

Segundo Barros (2002), o conceito de bioenergética utiliza o modelo holístico de saúde, na medida em que a propõe como envolvendo múltiplos aspectos biopsicossociais. Isto é, ao avaliar a saúde de uma pessoa, precisamos levar em conta as diversas dimensões que a envolvem, tais como aspectos físicos, fisiológicos, mentais, emocionais, religiosos, energéticos e ambientais

O conceito de bioenergética deu origem a uma forma de terapia conhecida como "Análise Bioenergética" , cuja proposta é uma integração homem-corpo-emoção-razão (SANTANA, 2006). A condução deste trabalho leva em conta alguns conceitos fundamentais da teoria de Reich: couraça muscular, segmentos da couraça muscular e algumas técnicas corporais que envolvem a postura grounding, a respiração e a massagem. A bioenergética tem origens na vegetoterapia, uma técnica terapêutica corporal criada por Wilhelm Reich, que possui, os mesmos princípios da Bioenergética, que seria o alívio das tenções à partir da liberação das couraças musculares adquiridas ao longo da vida.

Por conta do pouco material disponível na literatura científica, este estudo tem o propósito de discutir e categorizar o que se tem produzido sobre a temática, em periódicos indexados, na última década, numa tentativa também de dar mais visibilidade aos seus conceitos fundamentais.

Dessa forma, o objetivo do presente estudo foi analisar os artigos sobre Psicologia corporal, mais precisamente sobre a Análise Bioenergética, produzidos na última década, especificamente no período de 2003 a 2013. A proposta foi identificar e problematizar as temáticas mais abordadas nos artigos, como forma de contribuir como fonte de referência, tanto 
para a composição das políticas públicas para a saúde, quanto para outros contextos que incluam a Psicologia corporal e a Análise bioenergética.

Em resumo, o objetivo geral foi proceder uma revisão sistemática da literatura sobre a produção científica sobre a psicologia corporal, disponível na rede mundial, sobre nos últimos 10 anos, à partir de uma revisão sistemática da literatura. Para isso, foi necessário também proceder: a) uma categorização dos assuntos tratados nos artigos; b) descrever os artigos e suas origens (nacionalidade, periódico, população estudada), bem como, c) discutir as políticas públicas propostas, associadas aos referidos estudos.

Com relação ao método, trata-se de uma de revisão sistemática da literatura, onde utilizou-se também a técnica da análise de conteúdo para uma crítica dos resultados.

A pesquisa foi realizada, através de uma busca das informações nos bancos de dados Scielo e Biblioteca Virtual em Saúde - BVS, no período citado.

Por revisão sistemática, entenda-se uma estratégia de revisão da literatura, de maneira planejada, que possa responder a questões específicas. É descrita, principalmente em duas publicações: a CDR Report (KHAN, TER RIET, GLANVILLE, SOWDEN, KLEIJNEN, 2000), e a Cochrane Handbook (CLARKE e OXMAN, 2000). Esta última recomenda que, uma revisão sistemática deva seguir os seguintes passos: a) A formulação de uma pergunta de partida como passo inicial; b) A seleção do material para estudo. Neste caso, refere-se às fontes que serão utilizadas. c) Uma análise crítica dos estudos selecionados, quando proceder-se-á uma triagem do material selecionado inicialmente. A fase de coleta de dados. d) Análise das informações. Etapa na qual o pesquisador agrupará os estudos por semelhança, de acordo com os objetivos propostos; e) Interpretação dos dados. Nesta fase será dado realce às diferenças e semelhanças encontradas nos estudos selecionados, clarificando benefícios e/ou aplicabilidade, riscos, dentre outros aspectos que façam parte dos objetivos; f) Atualização da revisão. Neste caso, pode-se fazer possíveis críticas e/ou sugestões para melhorar os estudos subsequentes para atualização da temática ora estudada.

Segundo os autores Cook, Mulrow e Haynes (1997), uma revisão sistemática precisa ser específica, criteriosa e reproduzível, bem como baseada em resultados de pesquisas clínicas.

Para localização dos artigos, houve uma seleção inicial através dos títulos e resumos dos artigos que contivessem as palavras-chave: sobre análise bioenergética, bioenergética, terapia corporal e psicologia corporal. A escolha desses bancos de dados eletrônicos se deu, por se tratar dos mais populares e conhecidos do Brasil.

O Banco de dados Scielo - Scientific Electronic Library Online, é uma biblioteca virtual desenvolvida pela FAPESP - Fundação de Amparo à Pesquisa de São Paulo. Tem como parceira o BIREME - Centro Latino_Americano e do Caribe de Informação em Ciências da Saúde. Sua 
tarefa é abrigar periódicos científicos brasileiros avaliados de alta qualidade. Possuem uma metodologia comum de armazenamento da produção científica, em formato eletrônico. São duas importantes bases de dados que configuram-se como um rico instrumento de análise, permitindo vislumbrar recortes do impacto do aleitamento materno, nesta época, além de uma compreensão dos sub-temas mais discutidos.

Os artigos foram selecionados ao acaso, à medida que os mesmos apareciam na busca eletrônica por palavras-chave.

Com relação aos aspectos éticos, não se fez necessário o envio a um comitê de ética em pesquisa, por tratar-se de uma revisão da literatura.

Quanto à análise dos resultados, esta foi realizada tanto pela análise da qualidade das informações de acordo com os objetivos, como também através do método de Análise de Conteúdo Temática proposta por Bardin (2002), que tem como objetivo a busca de um sentido nas comunicações e de suas possibilidades em termos de significação, tanto explícitas quanto ocultas.

Inicialmente, se procedeu a constituição de um corpus, formado pelos artigos selecionados. Em seguida foi feita uma leitura flutuante para, posteriormente, proceder-se leituras mais intensivas, as quais permitiram uma melhor compreensão dos dados e sua codificação em categorias.

Segundo Vala (1986), a análise de conteúdos se constitui uma das técnicas mais recorrentes em pesquisas empíricas, notadamente nas ciências humanas e sociais, possibilitando inferências sobre a organização do sistema de pensamento através dos discursos. Nesta mesma direção, Bardin (2001), nos orienta que, a análise de conteúdo é um conjunto de técnicas para analisar sistematicamente as comunicações, visando obter indicadores que permitam a inferência de conhecimentos contidos nessas mensagens.

Neste estudo, optou-se por selecionar títulos e/ou frases nos artigos, que preencheram os critérios de inclusão, de acordo com as palavras-chave. Também foram consideradas as citações utilizadas nos textos, por denotarem uma escolha dos autores, como forma de fundamentação do seu discurso.

\section{Resultados}

Foram selecionados 15 artigos/publicações, que encontram-se listados na tabela 1, a seguir:

Id en line Revista de Psicologia. Ano 7, No. 20, Julho/2013 - ISSN 1981-1179.

Edição eletrônica em http://idonline.emnuvens.com.br/id 
Tabela 1 - Lista das publicações selecionadas.

\begin{tabular}{|c|c|c|}
\hline Publicações encontradas na internet & Categoria & Tipo \\
\hline $\begin{array}{l}1 \text { - SCOTTON, Suzana Z. A vertigem como um sinal de } \\
\text { transformação no processo psicoterapêutico. In: XVI ENCONTRO } \\
\text { PARANAENSE e XI CONGRESSO BRASILEIRO DE } \\
\text { PSICOTERAPIAS CORPORAIS, 2011. Anais. Curitiba: Centro } \\
\text { Reichiano, 2011. [ISBN-978-85-87691-21-7]. }\end{array}$ & 2 & Artigo \\
\hline $\begin{array}{l}2 \text { - BERGER, Rebeca. Corpo, Imagem e Subjetividade: } \\
\text { envelhecimento como processo vital. Paper oriundo de tese de } \\
\text { mestrado em gerontologia da Pontifícia Universidade Católica de } \\
\text { São Paulo. Programa de estudos de Pós-Graduação em Gerontologia. } \\
\text { São Paulo, 2007. }\end{array}$ & 2 & Artigo \\
\hline $\begin{array}{l}3 \text { - HOFFMANN, Catharina. Fazer saúde na cidade: contribuições } \\
\text { da clínica raichiana para a formação em saúde pública. In: XVII } \\
\text { ENCONTRO PARANAENSE e XII CONGRESSO BRASILEIRO } \\
\text { DE PSICOTERAPIAS CORPORAIS, 2012. Anais. Curitiba: Centro } \\
\text { Reichiano, 2012. [ISBN - 978-85-87691-22-4]. }\end{array}$ & 1 & Artigo \\
\hline $\begin{array}{l}4 \text { - CARVALHO, Maria Luiza M. Aprendizagem teórico-vivencial } \\
\text { da psicologia corporal em curso de graduação em psicologia. In: XV } \\
\text { ENCONTRO PARANAENSE e X CONGRESSO BRASILEIRO } \\
\text { DE PSICOTERAPIAS CORPORAIS, 2010. Anais. Curitiba: Centro } \\
\text { Reichiano, 2010. }\end{array}$ & 2 & Artigo \\
\hline $\begin{array}{l}5 \text { - CÂNDIDO, Paula E.F.; MATTOS, Daniela J. S. Bioenergética: } \\
\text { fundamentos e técnicas corporais. Lecturas: Educación Física y } \\
\text { Deportes. Revista Digital. Buenos Aires. Ano 14. N.131. Abril/2009. }\end{array}$ & 5 & Artigo \\
\hline $\begin{array}{l}6 \text { - TOSTA, Francisco. Trabalhos corporais em clínica psiquiátrica: } \\
\text { um enfoque da psicologia corporal. In: XIV ENCONTRO } \\
\text { PARANAENSE e IX CONGRESSO BRASILEIRO DE } \\
\text { PSICOTERAPIAS CORPORAIS, 2009. Anais. Curitiba: Centro } \\
\text { Reichiano, 2009. }\end{array}$ & 1 & Artigo \\
\hline $\begin{array}{l}7 \text { - NOGUEIRA, T. A. Grupo de movimento: conceituação, estado } \\
\text { da arte e aplicação na área educacional. Dissertação de mestrado. } \\
\text { Instituto de Psicologia da universidade de São Paulo. São Paulo. } \\
2010 .\end{array}$ & 5 & Dissertação \\
\hline $\begin{array}{l}8 \text { - LIMA, Déborah Maia de; SILVA NETO, Norberto Abreu e. } \\
\text { Danças brasileiras e psicoterapia: um estudo sobre efeitos } \\
\text { terapêuticos. Psic.: Teor. e Pesq., Brasília, v. } 27 \text {, n. 1, Mar. } 2011 \text {. }\end{array}$ & 3 & Artigo \\
\hline $\begin{array}{l}9 \text { - JEBER, Leonardo José. Educação pela autonomia através da } \\
\text { auto-regulação: uma perspectiva reichiana. Escritos educ., Ibirité, } \\
\text { v. } 5 \text {, n. } 1 \text {, jun. } 2006 \text {. }\end{array}$ & 2 & Artigo \\
\hline $\begin{array}{l}10 \text { - REGO, Ricardo Amaral. A clínica pulsional de Wilhelm Reich: } \\
\text { uma tentativa de atualização. Psicol. USP, São Paulo, v. 14, n. 2, } \\
2003 \text {. }\end{array}$ & 5 & Artigo \\
\hline $\begin{array}{l}11 \text { - RUSSO, Jane A.. Tornar-se terapeuta corporal: a trajetória } \\
\text { social como processo de "autoconstrução". Physis, Rio de Janeiro, } \\
\text { v. } 1, \text { n. } 2,1991 .\end{array}$ & 4 & Artigo \\
\hline $\operatorname{con}$ & & \\
\hline
\end{tabular}

Id en line Revista de Psicologia. Ano 7, No. 20, Julho/2013 - ISSN 1981-1179. 
12 - VECTORE, Celia. Psicologia e acupuntura: primeiras aproximações. Psicol. cienc. prof., Brasília, v. 25, n. 2, jun. 2005. 13 - AGUIAR, Fernando Henrique Rezende; CONCEICAO, Maria Inês Gandolfo. A Orientação Vocacional na perspectiva neoreichiana: contribuições do grounding. Rev. bras. orientac. prof, São Paulo, v. 9, n. 1, jun. 2008 .

14 - ROSSET, Janine. Interação familiar na anorexia nervosa: contribuições da psicologia corporal. Monografia. Centro Reichiano de psicologia Corporal. Curitiba, 2010.

15 - PATITUCCI, Daniel. Bioenergética e meditação aplicadas no controle da ansiedade em dependentes de substâncias psicoativas. Monografia. Centro Reichiano de psicologia Corporal. Curitiba, 2011.

Fonte: Internet (Maio/2013)

Das publicações encontradas, 12(doze) são artigos; 1(uma) é dissertação e 2(duas) são monografias. Um artigo foi do ano de 1991, este, apesar de ser muito antigo, foi incluído por se tratar de um importante estudo na área e também, por serem poucos os artigos encontrados na rede mundial de computadores, sobre a temática; um de 2003; um de 2005; um de 2006; um de 2007; um de 2008; dois de 2009; três publicações de 2010; três publicações de 2011 e um artigo de 2012. Portanto, 66,7\% dos estudos são relativamente recentes, isto é, referentes aos últimos cinco anos (2008 a 2012). Os outros 33,3\% são estudos entre 1991 a 2007. Os assuntos discutidos possibilitaram seu agrupamento em 5 categorias, a saber: 1 - Bioenergética aplicada (3 artigos - 20,0\%), 2- Reflexões em Psicologia corporal (4 artigos - 26,7\%); 3 - Efeitos terapêuticos (1 artigo - 6,6\%); 4 - Desenvolvimento pessoal (2 artigos - 13,3\%) e, 5 Fundamentos teóricos (5 artigos - 33,4\%). As categorias foram inspiradas nas possibilidades da análise bioenergética, despertadas à partir da literatura do material disponível.

A seguir uma descrição das categorias eliciadas.

\section{Categoria 1 - Bioenergética aplicada:}

Nesta categoria foram enquadrados os artigos que trataram sobre aplicações práticas da Bioenergética e da Análise bioenergética.

Três publicações foram incluídas nesta categoria. A primeira, um artigo de Hoffmann (2012), intitulado: "Fazer saúde na cidade: contribuições da clínica reichiana para a formação em saúde pública", discutiu uma experiência de grupo de movimento como possibilidade de diversificar as intervenções tradicionais em saúde pública. Foi uma oportunidade de refletir com os alunos dos $8^{\circ}$ ao $10^{\circ}$ semestre do curso de Psicologia, em Vitória no Espírito Santo, em estágio supervisionado, questões políticas associadas às neuroses. Tal trabalho tem base nos trabalhos de Wilhelm Reich (1927; 1933), que abordou conflitos humanos, ao mesmo tempo em 
que considerou os contextos, social e político. $\mathrm{O}$ autor acreditava no trabalho verbal de análise, associado às intervenções ativas no corpo, como descrito em sua obra "análise do Caráter (REICH, 1933). Segundo Hoffmann (2012), Reich levava em conta que, os problemas sócioeconômicos estariam na gênese dos distúrbios psíquicos. Ele acreditava que o sofrimento e a angústia do homem, são meros artefatos produzidos por conta das restrições sociais impostas à vida e ao corpo.

Neste sentido, e já que, os bloqueios e tensões musculares seriam impedimento da livre expressão emocional, a intervenção direta no corpo, favoreceria o acesso à estrutura de caráter do sujeito. Ou seja, ao seu conjunto de atitudes corporais, ora estereotipadas, quer seja no modo de falar, andar ou de se expressar.

Foram ministradas duas oficinas em duas semanas, para que os alunos se familiarizassem com os recursos do trabalho corporal, como possibilidade na promoção da saúde. A autora referiu que o trabalho com grupos de movimento, proposto inicialmente junto às comunidades não chegou a se efetivar. Porém, a abertura ao sensível e aos corpos proporcionadas aos alunos, produziu benefícios. Funcionou como uma preparação pessoal, diminuindo a carga sexista, normalmente associada a Reich e ajudando-os a liberar os sentimentos espontâneos de amor e ódio ambivalentes.

O segundo artigo, nesta categoria, tratou sobre: Trabalhos corporais em clínica psiquiátrica: um enfoque da psicologia corporal (TOSTA, 2009). Neste caso, o autor referiu um estágio de psicologia, em clínica psiquiátrica no ano de 2008. Neste estágio, através de trabalhos de Psicologia corporal e de técnicas da vegetoterapia e da Bioenergética com os pacientes, foi possível observar-se os efeitos práticos dessas técnicas nos mesmos.

$\mathrm{O}$ autor concluiu que, trabalhos que venham a promover e integrar autopercepção aos pacientes, estariam colaborando com o bem estar e a melhoria da sua qualidade de vida.

A terceira publicação foi uma monografia. Tratou sobre os benefícios e as limitações de um programa de prevenção da recaída, em pacientes dependentes de substâncias psicoativas, com base nas técnicas da Bioenergética e da Meditação (PATITUCCI, 2011). A ideia principal foi a redução dos níveis da sintomatologia relacionadas à abstinência. $\mathrm{O}$ autor reportou em suas conclusões que, fatores pessoais possuem uma forte interferência na recuperação dos pacientes. Além disso, constataram eficácia significativa nas possibilidades de recaída, à partir das técnicas vivenciadas.

Uma vez que as publicações foram selecionadas ao acaso, nos levou a crer que, as questões relativas à aplicação prática da Psicologia corporal e/ou da Análise bioenergética, parece pouco discutida na literatura disponível na internet, principalmente nas revistas científicas especializadas.

Id en line Revista de Psicologia. Ano 7, No. 20, Julho/2013 - ISSN 1981-1179. 


\section{Categoria 2 - Temáticas em Psicologia corporal:}

Nesta categoria específica, foram enquadradas 4 publicações, das 15 selecionadas para fazerem parte deste estudo. Isso representou $26,7 \%$ das publicações selecionadas ao acaso.

Entenda-se por Temáticas em psicologia corporal, os assuntos que discutem aspectos relacionados à natureza humana, nos quais sejam mencionadas associações desses com a psicologia corporal, tais como, envelhecimento, sexualidade, rigidez física e/ou fisiológica, aprendizagem, dentre outros.

Os artigos/publicações selecionadas trataram basicamente do seguinte: um artigo se reportou a Vertigem como um sinal de transformação no processo psicoterapêutico (SCOTTON, 2011). Neste caso, a autora relacionou a vertigem como uma experiência de somatização, de apropriação do ego corporal. Revela a autora que o olhar psicocorporal reichiano nos informa ser este sintoma, revelador de angústia, por inflexibilidade afetiva e corporal. A eterna busca da estabilidade e do controle, quando os mesmos parecem "balançar" de um lado para o outro, numa indefinição, de certa forma, insuportável pelo sujeito. A autora conclui, refletindo a possibilidade da vertigem ser um indicativo do momento do sujeito de desejar sair da rigidez, fazendo-se necessária a compreensão de que, este sintoma aparece num corpo biopsíquico cerceado por fortes mecanismos de proteção.

O segundo artigo desta categoria, abordou o envelhecimento como um processo vital (BERGER, 2007). Este trabalho reporta uma atividade utilizando-se a abordagem psicocorporal, fundamentada nos conceitos da Bioenergética com nove mulheres, com idades entre 63 e 86 anos. A idéia foi privilegiar o contato com pessoas com diferentes e semelhantes características, tais como força física, vigor, papéis sociais, características psicológicas e cognitivas, de maneira a ser possível observar-se também em processo de mudança, porém, sob novas condições de longevidade.

O terceiro artigo nesta categoria, foi referente a aprendizagem teórico-vivencial da psicologia corporal em curso de graduação em Psicologia (CARVALHO, 2010).

O artigo discorre sobre a inclusão de trabalhos práticos de psicologia corporal, em sintonia com o conteúdo teórico das aulas, desenvolvidos em períodos de 15 a 30 minutos por dia. Os exercícios envolveram trabalhos de consciência psicocorporal com os alunos sentados, deitados ou mesmo em pé. Tiveram o objetivo de permitir um contato introdutório dos mesmos com a vivência psicocorporal. As vivências incluíram também a expressão verbal das experiências, proporcionando uma reflexão coletiva, didaticamente relacionada aos conteúdos estudados. O estudo relata também uma avaliação trimestral do trabalho por parte dos envolvidos, revelando-se uma experiência satisfatória para o grupo. Em geral os alunos descreveram os benefícios, não só para a melhoria do seu conhecimento, mas para um 
relaxamento de suas tensões psicocorporais e seu bem-estar na sala de aula. Essa experiência levou alguns alunos de Psicologia a introduzirem breves trabalhos psicocorporais em suas práticas como estagiários de Psicologia no Serviço de Psicologia Aplicada da faculdade.

Concluiu que a prática do ensino-aprendizagem da psicologia corporal desenvolvida na Faculdade, objeto do estudo em questão, demonstrou sua viabilidade e interesse dos alunos, que chegaram a se queixar da ausência desses conteúdos e abordagem ao longo do curso de graduação. A autora conclui apresentando uma proposta de incorporação dos conteúdos da obra de Wilhelm Reich e de outros autores de psicologia corporal na grade curricular de graduação em Psicologia, bem como a ampliação de estágios na área.

O quarto artigo nesta categoria, considera a educação pela autonomia através da autoregulação numa perspectiva reichiana (JEBER, 2006).

Neste caso, o autor apresenta uma relação entre o conceito de autonomia (que considera o grande objetivo a ser alcançado na formação educacional) e o conceito de auto-regulação (da psicologia política de Wilhelm Reich).

A autorregulação é descrita como capacidade biológica e natural que revela nosso potencial para a autonomia. Reflete que, a partir dessa capacidade natural de funcionar dos indivíduos, é que se pode compreender a ideia de uma organização social. Que o respeito a essa premissa é condição necessária a uma cultura de respeito a maneira particular de ser, dos indivíduos que a compõem. Propõe uma relação dinâmica entre indivíduo, natureza e sociedade. O autor cita Fritjof Capra (2002) para expressar suas idéias:

O principal desafio deste novo século será a construção de comunidades ecologicamente sustentáveis, organizadas de tal modo que suas tecnologias e instituições sociais não prejudiquem a capacidade intrínseca da natureza sustentar a vida. Os princípios sobre os quais se erguerão as nossas futuras instituições sociais terão de ser coerentes com os princípios de organização que a natureza fez evoluir para sustentar a teia da vida (JEBER, 2006, p.1 apud CAPRA, 2002)

O autor conclui que a educação baseada na auto-regulação nos faz refletir sobre a relação entre natureza e cultura em nosso contexto ocidental. E que há um tipo de pensamento, em nosso cotidiano intelectual que crê numa cultura que domina a natureza e que lhe é superior. A cultura de que tudo podemos diante da natureza. $\mathrm{O}$ autor considera esse, um dos maiores erros da humanidade. Pois, os ecologistas têm mostrado que, a na verdade, a natureza é que tem primazia sobre a cultura. A força da natureza tem sido capaz de exigir uma reflexão dos homens com relação à necessidade de um maior respeito a sua condição de elemento da natureza. $\mathrm{E}$ continua,

Id en line Revista de Psicologia. Ano 7, No. 20, Julho/2013 - ISSN 1981-1179. 
Há um momento em que o desrespeito da cultura pela natureza é tão grande que a natureza simplesmente responde de um modo que nós podemos perceber que ela não se importa com a cultura humana, porque sua finalidade é manter a vida planetária e cósmica e, se os humanos ameaçam a vida, podem ser dizimados, assim como já aconteceu com outras espécies sobre a face da Terra. (JEBER, 2006. p. 2)

Portanto, uma clara referência ao que entende Reich (1975) por auto-regulação, segundo o autor, esta implicaria no fato de que, a vida humana é sábia e por isso, sabe muito bem quais as suas necessidades. $\mathrm{O}$ desconhecimento dos homens a essa verdade implícita é que cria todas as dificuldades e encouraçamentos. Indicam que o homem não compreendeu que a natureza da vida se expressa no próprio corpo humano, indicando-lhe como a vida funciona e como deveria ser conduzida pela cultura (ALBERTINI, 1994).

Dessa forma, o autor conclui que, educar pela auto-regulação, consiste em saber que as pessoas são capazes de entrar em contato com os próprios sentimentos, bem como expressá-los de maneira livre e autêntica. Esta, deve ser posta em prática desde o nascimento, de forma a permitir a expressão sincera dos sentimentos infantis. Acrescenta que o cuidado com os sentimentos é fundamental para um desenvolvimento humano sadio, sendo em contraponto, nociva uma pedagogia ou uma filosofia, por demais intelectualizada.

Em resumo os quatro artigos abordaram temáticas importantes, desde as questões ligadas a somatização, tendo os exercícios de bioenergética, o papel de proporcionar uma maior consciência corporal, promotora do resgate da saúde emocional; passando pela questão do envelhecimento e condições para a longevidade; bem como uma avaliação das práticas de ensino da Psicologia corporal na universidade; culminando com considerações sobre a educação para a auto-regulação, numa perspectiva reichiana, como pré-condição para uma melhor compreensão de si mesmo.

Como as temáticas em psicologia Corporal nos parece um campo muito abrangente, seria óbvio se esperar muito mais artigos disponíveis na internet, o que não aconteceu. Quatro artigos são incipientes para uma maior compreensão da análise bioenergética e seus benefícios à saúde, de uma maneira geral.

São temáticas importantes, mas que carecem de maiores estudos com outros grupos sociais, ampliando dessa forma, o arsenal teórico existente sobre os assuntos tratados. 


\section{Categoria 3 - Efeitos terapêuticos:}

Nesta categoria foram enquadrados os artigos que se propuseram a discutir os efeitos terapêuticos associados à dança e/ou aos exercícios bioenergéticos. Apenas um artigo foi percebido como pertencendo a esta categoria: Danças brasileiras e psicoterapia: um estudo sobre efeitos terapêuticos, dos autores Déborah Maia de Lima e Norberto Abreu Silva Neto, de 2011. O mesmo discorre sobre as abordagens terapêuticas com enfoques corporais, como a Bioenergética, enquanto linguagem corporal. Justifica o estudo, explicitando que a dança é um recurso psicoterapêutico, que elicia elementos artísticos ou estimulantes da criatividade, que tem sido apontada como possibilidade de intervenção em contextos psiquiátricos ou terapêuticos (Abreu e Silva, 1977; Castro, 1992; Koch, Morlinghaus e Fuchs, 2007; Thulin, 1997). E que, mesmo assim, são poucos os estudos sobre a utilização da cultura popular, principalmente das danças populares brasileiras, como ferramenta na clínica psicoterápica.

No campo da saúde, os autores consideram ainda incipiente, a aplicação dessa especificidade cultural, ainda que seja facilitadora do desenvolvimento da criatividade elou do crescimento pessoal do indivíduo. O autor justifica ainda a sua conclusão, citando estudos de Koch, Morlinghaus e Fuchs (2007), que investigaram os efeitos de intervenção terapêutica utilizando-se a dança - movimento, enquanto terapia na diminuição dos estados depressivos, bem como no aumento da vitalidade em pacientes psiquiátricos. Os pacientes mostraram como resultado, uma melhora significativa em seus quadros depressivos, aliado a um aumento da vitalidade.

E acrescenta,

Trabalhos como os de Castro (1992); Koch e cols, (2007) Peto (2000), Farr (1997), Fux (1983), Chace (conforme citado por Abreu e Silva, 1977), entre outros, direcionam para um terreno promissor entre a relação do trabalho psicológico com a arte da dança. Estas "terapias pela dança" propiciam aumento de auto-estima, de saúde corporal, de vitalidade, de autoconsciência, além de uma ampliação da consciência corporal e de uma apropriação do paciente de seu corpo. Esse é um fator fundamentalmente valioso na busca de uma melhor qualidade de vida. (LIMA, ABREU e SILVA NETO, 2011)

Concorda com Fux (1983) quando também propõe a importância da voz e da música, como algo que exerce um papel fundamental no trabalho corporal.

Além de utilizar a voz em suas sessões, a música exerce um papel importante no trabalho de Maria Fux. São utilizadas tanto músicas medievais, gravações do clássico, barroco, músicas folclóricas como músicas contemporâneas transmitidas pela mídia, em rádio e televisão. (LIMA, ABREU e SILVA NETO, 2011) 
Em resumo, este trabalho corroborou estudos de outros autores no tocante a diversos aspectos, a saber: a) o movimento é compreendido como algo revelador das nossas emoções e processos mentais (CREMA, 1983); b) a dana se caracteriza pela utilização do movimento como uma linguagem simbólica, geradora de significados (FREIRE, 2001); c) a dança auxilia a expressão e a comunicação, que se dá através de movimentos (FORTIN, 1999); d) Há uma relevância particular nas celebrações populares, que podem funcionar como valiosos resgates da alegria, expressão da criatividade e formação de vínculos. Portanto um rico campo para outras investigações acadêmicas acerca da saúde física e emocional.

\section{Categoria 4 - Desenvolvimento pessoal:}

Nesta categoria foram enquadrados os artigos que discutiram a análise bioenergética, numa perspectiva de desenvolvimento pessoal. Dois artigos foram enquadrados nesta categoria, a saber: Tornar-se terapeuta corporal: a trajetória social como processo de "autoconstrução", de Jane A. Russo (1991) e, A Orientação Vocacional na perspectiva neo-reichiana: contribuições do grounding, de Fernando Henrique R. Aguiar e Maria Inês G. Conceição (2008).

O primeiro, discorre sobre as terapias corporais, enquanto possibilidade ocupacional no processo de autoconstrução do indivíduo. Inicia fazendo um resgate do surgimento e florescimento das terapias corporais, abordando principalmente a questão do Rio de Janeiro, onde na década de 70 houve uma grande difusão social da psicanálise, havendo inclusive uma espécie de monopólio dos médicos sobre o título de psicanalista.

Chama a atenção sobre o surgimento, nos anos 80 de um sem número de práticas e terapias alternativas, causando uma certa tensão entre os profissionais, principalmente os médicos psicanalistas e os leigos.

Como as terapias corporais eram calcadas na teoria Reichiana, havia uma legitimidade que a embasava e, dessa forma, foi se afirmando cada vez mais como promotoras de uma autoconsciência. Privilegiando o trabalho com o corpo, sede dos impulsos e instintos naturais, trás a possibilidade de expressões mais naturais, espontâneas e biológicas, em oposição a artificialidade da sociedade e à racionalidade da linguagem falada. "A palavra pode esconder as verdadeiras emoções e sentimentos, o corpo não" (...) "É através do corpo, que se chega à pessoa como ela é, naturalmente." (RUSSO, 1991, p.121).

Segundo a autora,

Id en line Revista de Psicologia. Ano 7, No. 20, Julho/2013 - ISSN 1981-1179. 
As teorias que servem de base ás Terapias corporais, por serem psicológicas, são capazes de, ao mesmo tempo, justificar a negação da sociedade (do universo social de origem e das limitações que se representava) e transformar o fazer-se a si mesmo, em autodescoberta. É na verdade, negando o social que o sujeito descobre a si mesmo. Essa autodescoberta (ou autoconstrução) se faz através do corpo. (RUSSO, 1991, p.122).

A autora se reporta ao grupo pioneiro no Rio de Janeiro, que, à margem das questões burocráticas acadêmicas, se constituiu, valendo-se de um trabalho corporal baseado em vivências e exercícios. Inicialmente um tanto disperso e oriundos das mais diversas formações/treinamentos, no Brasil e no exterior, a saber: em Bioenergética, Biodinâmica, Biossíntese, Massagem reichiana, vegetoterapia, Massagem de Esalem, Radix, Somaterapia (com Roberto Freire), dentre outras, além da própria psicanálise.

Em resumo, somente à partir de 1989 é que as instituições formadoras começaram a surgir com oferta de diferentes linhas de terapia corporal, dando origem, aqui no Brasil, a uma melhor definição das fronteiras sobre quem seria ou não, autorizado a exercer a prática clínica em terapia reichiana, ou quem poderia se habilitar a fazer uma formação nesta linha.

No mais, um artigo com conotações históricas, mas que basicamente, tratou sobre a importância da formação do terapeuta corporal, tanto no sentido de uma luta por uma delimitação do espaço profissional, quanto da valorização de se efetivar o reconhecimento de ser um trabalho importante do ponto de vista do desenvolvimento pessoal.

O segundo artigo, resgata as contribuições do grounding e de outros exercícios bioenergéticos, para se alcançar e desenvolver a autonomia e melhorar a autopercepção dos indivíduos.

Trata-se de um estudo que descreve, basicamente, uma experiência de trabalhos corporais com um grupo de dez adolescentes, todos em processo de orientação vocacional. A ideia foi possibilitar a esses adolescentes uma melhor consciência de si e, uma maior percepção corporal, com a finalidade de melhorar seu processo de decisão e, agregar mais confiança na escolha profissional.

Segundo os autores,

O grounding apoia-se na teoria bioenergética e da Core Energetics, que possuem em suas bases teóricas, um profundo conhecimento sobre a dinâmica energética e muscular associada ao trabalho terapêutico com o corpo, impossível de se abordar em poucas páginas. (AGUIAR e CONCEIÇÃO, 2008, p.126)

E ainda, 
Os efeitos e consequências do trabalho de grounding são bem conhecidos e percebidos no trabalho terapêutico - seja individual ou em grupos - tendo sido descrito na literatura específica a partir da prática empírica (AGUIAR e CONCEIÇÃO, 2008, p.126, apud WEIGAND, 2006)

O trabalho foi dividido em oficinas, com uma estrutura básica que consistiu de quatro etapas: 1 - uma conversa inicial sobre a escolha de uma profissão; 2- exercícios corporais bioenergéticos que apresentem alguma relação com o aumento da autoexpressão e fortalecimento da identidade; 3 - atividades próprias da oficina, tais como coleta de informações sobre a pessoa, a família, o contexto, seguido de jogos e dinâmicas; 4 - compartilhamento sobre os exercícios e atividades.

Os resultados levaram os autores a crer que, apesar de alguns dos adolescentes não terem chegado ao final dos trabalhos sem uma definição inicial sobre sua escolha profissional, diversas questões pessoais foram refletidas e, o trabalho corporal energético parece ter possibilitado um aumento da concentração e da autopercepção, na medida em que foram tocando pontos mais sensíveis das histórias individuais.

Sendo a Análise Bioenergética tida como promotora de uma melhor qualidade de vida, seria de se esperar um maior número de artigos encontrados, que pudessem ser enquadrados nesta categoria, o que não aconteceu.

\section{Categoria 5 - Fundamentos teóricos:}

Finalmente, nesta categoria foram enquadrados cinco artigos que discutiram, direta ou indiretamente, os fundamentos teóricos relacionados à psicologia corporal, a saber: 1) Bioenergética: fundamentos e técnicas corporais, das autoras Paula Cândido e Daniela Mattos (2013); 2) Grupo de movimento: conceituação, estado da arte e aplicação na área educacional, de Francisco Tosta (2009); 3) A clínica pulsional de Wilhelm Reich: uma tentativa de atualização, de Ricardo Amaral Rego (2013); 4) Psicologia e acupuntura: primeiras aproximações, de Célia Vectore (2005) e; 5)Interação familiar na anorexia nervosa: contribuições da Psicologia corporal, uma monografia de Janine Rosset (2013).

$\mathrm{O}$ primeiro artigo desta categoria versa sobre a Bioenergética, seus fundamentos e técnicas corporais e, foi escrito pelas autoras: Paula Emanuela F. Cândido e Daniela J. da Silva Mattos em 2006.

Id en line Revista de Psicologia. Ano 7, No. 20, Julho/2013 - ISSN 1981-1179. 
As autoras fazem todo um levantamento conceitual da bioenergética enquanto maneira de se entender a personalidade em termos corporais. Desde os processos de produção de energia através da respiração, metabolismo e descarga, até os movimentos e expressão dos sentimentos.

É uma revisão da literatura, analisando as pesquisas científicas que se relacionaram aos fundamentos e técnicas corporais em bioenergética. Foram aprofundados conceitos que embasam os princípios da bioenergética, tais como couraça muscular e segmentos corporais, bem como a dissolução dos mesmos através de massagens, respiração e exercícios.

Discorre sobre a vegetoterapia e conclui pela necessidade de mais estudos experimentais, conduzidos com rigor científico, que comprovem a teoria.

Em resumo, a ideia foi a difusão de trabalhos na área, como forma de motivar e despertar o interesse pela bioenergética.

O segundo trabalho nesta categoria, foi uma dissertação de mestrado. Mais precisamente, uma pesquisa teórica sobre grupos de movimento, uma estratégia utilizada para intervenção em grupos, com raíses na psicologia corporal. Esta estratégia baseia-se em introduzir nos grupos, vivências promotoras do alívio de tensões físicas e emocionais.

O trabalho discutiu, entre outras coisas, sobre a utilização de grupos de movimento e possíveis aplicações da abordagem corporal na área educacional.

Foram pesquisados 30 trabalhos e, em todos houve indicações de contribuições positivas sobre a prática efetuada nos grupos.

Concluiu-se pela necessidade de maiores estudos que problematizem a prática grupal como uma ferramenta, que deva ser incentivada, em trabalhos terapêuticos corporais.

O terceiro artigo objetivou uma atualização sobre a clínica pulsional de Wilhelm. Foi escrita por Ricardo Amaral Rego em 2003, com a proposta de contribuir com a fundamentação teórica em psicologia corporal, inspirada em Reich e na teoria freudiana das pulsões.

O artigo é uma tentativa de explicar teoricamente, elementos da abordagem reichiana, quando envolvidos numa dinâmica psíquica baseada no conflito entre pulsão e defesa. Discorre sobre a teoria e da técnica da psicologia corporal, desde a metafísica freudiana, até os pressupostos biológicos e energéticos de reich.

O autor procedeu um vasto levantamento teórico sobre a psicologia biodinâmica de Gerda Boyesen (1986), sobre o paradigma pulsional, análise da resistência e o fenômeno da transferência, descritos por Wagner (2003 e SAMSON (2002). Questões relacionadas a libido (MEZAN, 1996); inconsciente (FREUD, 1915/1974); a questão dos arquétipos e outros inconscientes (STEVENS e PRICE, 1996); padrões musculares (KELEMAN, 1992, 1995), dentre outros.

Id en line Revista de Psicologia. Ano 7, No. 20, Julho/2013 - ISSN 1981-1179. 
Dentre suas principais conclusões, o autor acredita ser possível a descrição de uma clínica da psicoterapia corporal, tendo por base a teoria freudiana das pulsões, mas que,

O paradigma pulsional freudiano não dá conta de todas as possibilidades e propostas da psicoterapia corporal contemporânea. Talvez se possa dizer que o conflito entre pulsão e defesa é um modelo necessário, mas não suficiente, para compreender a clínica reichiana atual.

Em resumo, a contribuição maior do artigo, é a revelação da idéia reichiana sobre a participação do aparelho locomotor e do aparelho respiratório, na dinâmica psíquica humana. Mas o autor acredita que este tema merece um aprofundamento teórico, promotor de debates, tanto sobre sua metodologia clínica, quanto sobre o seu embasamento científico biológico e no âmbito das neurociências.

Outras contribuições teóricas vão no sentido de que Freud (1905/1972), já descrevia a importância das zonas erógenas oral, anal e genital, ressaltando que qualquer outra parte do corpo, também poderia adquirir a mesma suscetibilidade a estímulos, podendo tornar-se uma zona erógena. Portanto, Reich amplia os horizontes do corpo erógeno, demonstrando possibilidades já descritas por Freud. Isso facilitou sobremaneira a compreensão do homem de maneira a tornar possível um trabalho clínico, psico-corporal.

$\mathrm{O}$ quarto artigo discorreu sobre as possibilidades de se utilizar a acupuntura como mais um instrumento, na prática profissional dos psicólogos, de acordo com uma resolução número 05/2002 do Conselho Federal de Psicologia. O trabalho apresenta uma série de conceitos teóricos relacionados com a acupuntura, numa visão mais holística da saúde. Faz uma revisão acurada da literatura sobre o assunto, demonstrando a pertinência do uso da acupuntura em tratamento de patologias mentais.

Foi incorporado ao rol de artigos escolhidos, por se tratar de uma temática polêmica, e por ter a característica de ser uma intervenção direta no corpo. Porém, o artigo é de 2005 e, mesmo tendo sido autorizado por mais de dez anos, esta técnica foi desautorizada para uso por profissionais psicólogos em 2013, pela justiça brasileira, mais precisamente pelo Superior Tribunal de Justiça (STJ), por entender que o exercício da acupuntura é semelhante a um procedimento médico invasivo, ainda que mínimo.

De acordo com o Conselho Federal de Medicina (CFM), a acupuntura, enquanto técnica, é considerada uma especialidade médica. Desde 2002, o Conselho Federal de psicologia, utilizava-se da Associação Brasileira de Acupuntura, para fiscalização dos procedimentos por profissionais psicólogos. 
Em resumo, um artigo robusto, bem embasado teoricamente, apresentando trabalhos que certificam e recomendam o uso da acupuntura como prática complementar ao tratamento psicológico, dentre outros benefícios, como promotora de relaxamento, diminuindo a ansiedade e, na redução dos transtornos gerados pela quimioterapia em pós-operatórios.

O quinto artigo discutiu as contribuições da Psicologia corporal na interação familiar em casos de anorexia nervosa. Neste caso, uma monografia de Janine Rosset (2010), publicada pelo centro Reichiano de psicologia corporal. Utilizou-se do método de revisão bibliográfica da literatura na área, e demonstrou a necessidade de se considerar também este aspecto, nas intervenções terapêuticas.

Em resumo, observou-se muitos artigos de revisão da literatura, demonstrando ser essa temática, ainda carente de uma discussão maior, em seus mais diversos aspectos e também, para ampliação das suas várias possibilidades e clientela.

Os trabalhos de revisão da literatura tendem a ser uma excelente contribuição, uma vez que amiúdam determinado aspecto teórico, ampliando os conceitos num campo mais específico da teoria.

No presente trabalho, observou-se uma ampliação nos seguintes campos: Dos fundamentos e técnicas da bioenergética; Dos grupos de movimento; Da clínica pulsional e sua relação com a psicanálise de Freud; Da questão da Psicologia e a Acupuntura e, Da questão da interação familiar e uso da Psicologia corporal, especificamente nos casos de anorexia nervosa. Portanto, demonstrando um sem número de possibilidades dentro da psicologia corporal que ainda carecem de maiores estudos e discussões que os atualizem no tempo, espaço e nos diversos grupos sociais.

\section{Conclusão}

De uma maneira geral, observou-se uma riqueza de possibilidades na utilização da psicologia corporal, enquanto ferramenta terapêutica, mas é escassa a disponibilidade de artigos, publicados em periódicos indexados, que abordem temáticas relacionadas à psicologia corporal.

Apesar das inúmeras possibilidades em termos de saúde, que a análise bioenergética pode proporcionar, comprovadas e descritas em muitos artigos científicos, praticamente não existem políticas públicas no Brasil que considerem sua inserção, no campo da saúde coletiva como ferramenta complementar. 
É possível que, o pouco acesso a literatura especializada nos veículos de comunicação de massa, possam minimizar a percepção de um maior número de pessoas sobre os benefícios da análise bioenergética, não somente na área da saúde, como também na educação e nas organizações, de uma maneira geral.

Recomenda-se que as entidades brasileiras que lidam com a psicologia corporal e bioenergética, discutam a possibilidade da utilização da grande rede social que é a internet, para formalizarem um instrumento que promova uma maior divulgação de trabalhos e pesquisas, que possam oferecer suporte a teoria, contemplando as mais diversas possibilidades e os mais diversos grupos sociais. Iniciativas dessa natureza, certamente tornariam mais acessível o conhecimento de temáticas sobre a psicologia corporal, aos que desejam utilizar-se de fontes para seus trabalhos acadêmicos.

É importante também uma maior organização das entidades que trabalham com a psicologia corporal, no sentido de implementarem ações que possam sensibilizar os gestores públicos, inclusive com propostas que visem oferecer essa modalidade de tratamento ao público, principalmente aos mais carente de assistência.

\section{Referências}

ABREU e SILVA, N. N. A Dança: uma arte a serviço da terapia. Dissertação de Mestrado, Universidade de São Paulo, São Paulo, 1977.

AGUIAR, Fernando Henrique Rezende; CONCEICAO, Maria Inês Gandolfo. A Orientação Vocacional na perspectiva neo-reichiana: contribuições do grounding. Rev. bras. orientac. prof, São Paulo, v. 9, n. 1, jun. 2008 .

ALBERTINI, Paulo. Reich: história das idéias e formulações para a educação. Editora Ágora, 1994.

BERGER, Rebeca. Corpo, Imagem e Subjetividade: envelhecimento como processo vital. Paper oriundo de tese de mestrado em gerontologia da Pontifícia Universidade Católica de São Paulo. Programa de estudos de Pós-Graduação em Gerontologia. São Paulo, 2007. 
CÂNDIDO, Paula E.F.; MATTOS, Daniela J. S. Bioenergética: fundamentos e técnicas corporais. Lecturas: Educación Física y Deportes. Revista Digital. Buenos Aires. Ano 14. N.131. Abril/2009.

CARVALHO, Maria Luiza M. Aprendizagem teórico-vivencial da psicologia corporal em curso de graduação em psicologia. In: XV ENCONTRO PARANAENSE e X CONGRESSO BRASILEIRO DE PSICOTERAPIAS CORPORAIS, 2010. Anais. Curitiba: Centro Reichiano, 2010.

CAPRA, Fritjof. As conexões ocultas: ciência para uma vida sustentável. São Paulo: Cultrix, 2002.

CASTRO, E. D. A Apropriação de si mesmo através da dança. Dissertação de Mestrado, Universidade de São Paulo, São Paulo, 1992.

CREMA, R. Psicodança e Análise Transacional: Uma proposta de Integração ( $3^{\text {a }}$ Ed.). Brasília: H. P. MendesFortin, S. (1999). Educação Somática: Novo Ingrediente da Formação Prática em Dança (tradução Márcia Strazzacappa). Cadernos GIPE - CIT, no 2. Estudos do Corpo. Salvador: UFBA, 1983.

FARR, M. The Role of Dance/Movement Therapy in Treating At-Risk African American Adolescents. The Arts in Psychoterapy, 24(2), 1997. P.183-191.

FREIRE, I. Dança-Educação: O Corpo e o Movimento no Espaço do Conhecimento. Caderno Sedes, 21(53), 2001.p. 31-55

FREIRE, I. (2001). Dança-Educação: O Corpo e o Movimento no Espaço do Conhecimento. Caderno Sedes, 21(53), 2001, 31-55.

FREUD, S. Os instintos e suas vicissitudes. In S. Freud, Edição standard brasileira das obras psicológicas completas de Sigmund Freud (Vol. 14, pp. 129-162). Rio de Janeiro: Imago, 1969. (Trabalho original publicado em 1915) 
Três ensaios sobre a teoria da sexualidade. In S. Freud, Edição standard brasileira das obras psicológicas completas de Sigmund Freud (Vol. 7, pp. 123-250). Rio de Janeiro: Imago, 1972. (Trabalho original publicado em 1905

O inconsciente. In S. Freud, Edição standard brasileira das obras psicológicas completas de Sigmund Freud (Vol. 14, pp. 185-251). Rio de Janeiro: Imago, 1974 a. (Trabalho original publicado em 1915)

Repressão. In S. Freud, Edição standard brasileira das obras psicológicas completas de Sigmund Freud (Vol. 14, pp. 169-182). Rio de Janeiro: Imago, 1974 b. (Trabalho original publicado em 1915)

FORTIN, S. (1999). Educação Somática: Novo Ingrediente da Formação Prática em Dança (tradução Márcia Strazzacappa). Cadernos GIPE - CIT, no 2. Estudos do Corpo. Salvador: UFBA, 1999.

FUX, M. (1983). Dança experiência de Vida. 4ª Ed. São Paulo: Summus, 1983.

HOFFMANN, Catharina. Fazer saúde na cidade: contribuições da clínica raichiana para a formação em saúde pública. In: XVII ENCONTRO PARANAENSE e XII CONGRESSO BRASILEIRO DE PSICOTERAPIAS CORPORAIS, 2012. Anais. Curitiba: Centro Reichiano, 2012. [ISBN - 978-85-87691-22-4].

JEBER, Leonardo José. Educação pela autonomia através da auto-regulação: uma perspectiva reichiana. Escritos educ., Ibirité, v. 5, n. 1, jun. 2006 .

KELEMAN, S. Padrões de Distresse. São Paulo: Summus, 1992.

Corporificando a Experiência. São Paulo: Summus, 1995.

KOCK, S., MORLINGHAUS, K., e FUCHS, T. The Joy Dance - Specific Effects of a Single Dance Intervention on Psychiatric Patients with Depression. The Arts in Psychotherapy, 34, 2007. $340-349$. 
LIMA, Déborah Maia de; SILVA NETO, Norberto Abreu e. Danças brasileiras e psicoterapia: um estudo sobre efeitos terapêuticos. Psic.: Teor. e Pesq., Brasília, v. 27, n. 1, Mar. 2011 .

MEZAN, R. Paradigmas e modelos na psicanálise atual. In N. M. Pellanda \& L. E. C. Pellanda (Orgs.), Psicanálise Hoje: Uma Revolução do Olhar (pp. 347-355). Petrópolis, RJ: Vozes, 1996.

NOGUEIRA, T. A. Grupo de movimento: conceituação, estado da arte e aplicação na área educacional. Dissertação de mestrado. Instituto de Psicologia da universidade de São Paulo. São Paulo. 2010.

REGO, Ricardo Amaral. A clínica pulsional de Wilhelm Reich: uma tentativa de atualização. Psicol. USP, São Paulo, v. 14, n. 2, 2003.

REICH, Wilhelm. A função do orgasmo (1927). São Paulo: Brasiliense, 1975/1984.

Análise do Caráter (1933). São Paulo: Martins Fontes, 1995/1998.

ROSSET, Janine. Interação familiar na anorexia nervosa: contribuições da psicologia corporal. Monografia. Centro Reichiano de psicologia Corporal. Curitiba, 2010.

RUSSO, Jane A.. Tornar-se terapeuta corporal: a trajetória social como processo de "autoconstrução". Physis, Rio de Janeiro, v. 1, n. 2, 1991 .

SAMSON, A. Transferência e Contratransferência em Psicoterapia Corporal. São Paulo. 2002. Publicação eletrônica disponível em www.ibpb.com.br .

SCOTTON, Suzana Z. A vertigem como um sinal de transformação no processo psicoterapêutico. In: XVI ENCONTRO PARANAENSE e XI CONGRESSO BRASILEIRO DE PSICOTERAPIAS CORPORAIS, 2011. Anais. Curitiba: Centro Reichiano, 2011. [ISBN 978-85-87691-21-7].

STEVENS, A., e PRICE, J. Evolutionary Psychiatry. A New Beginning. London: Routledge, 1996. 
PATITUCCI, Daniel. Bioenergética e meditação aplicadas no controle da ansiedade em dependentes de substâncias psicoativas. Monografia. Centro Reichiano de psicologia Corporal. Curitiba, 2011.

PETO, A. C. Terapia Através da Dança com Laringectomizados: Relato de Experiência. Revista Latino-Am.de Enfermagem,. 8(6), 2000. P. 35-39.

THULIN, K. When Words Are Not Enough: dance therapy as a method of treatment for patients with psychosomatic disorders. American Journal of Dance Therapy, 19(1), 1997. P. $25-43$.

TOSTA, Francisco. Trabalhos corporais em clínica psiquiátrica: um enfoque da psicologia corporal. In: XIV ENCONTRO PARANAENSE e IX CONGRESSO BRASILEIRO DE PSICOTERAPIAS CORPORAIS, 2009. Anais. Curitiba: Centro Reichiano, 2009.

VECTORE, Celia. Psicologia e acupuntura: primeiras aproximações. Psicol. cienc. prof., Brasília, v. 25, n. 2, jun. 2005 .

WAGNer, C. M. A Transferência na Clínica Reichiana. São Paulo: Casa do Psicólogo, 2003.

Como citar este artigo (Formato ISO):

OLIVEIRA, G.F.; SILVA, R.C.A. e ROLIM, S.G. Análise Bioenergética: uma revisão sistemática da literatura. Id on Line Revista de Psicologia, Julho de 2013, vol.7, n.20, p. 75-96. ISSN 1981-1189. DOI: 10.14295/idonline.v7i20.238 